\title{
Beyond the Big Five: does grit influence the entrepreneurial intent of university students in the US?
}

\author{
Nikolaus T. Butz ${ }^{1 *}$ (D), Sheila Hanson ${ }^{2}$, Patrick L. Schultz ${ }^{2}$ and Marissa M. Warzynski ${ }^{1}$
}

\footnotetext{
* Correspondence: nbutz@uwsp.edu ${ }^{1}$ University of Wisconsin - Stevens Point, 1901 Fourth Ave, Stevens Point, WI 54481, USA

Full list of author information is available at the end of the article
}

\begin{abstract}
The purpose of this study was to explore the relationship between grit and entrepreneurial intent. Grit involves maintaining effort and interest in the pursuit of long-term goals, despite adversity, stagnation, or failure. Entrepreneurial intentions are a well-established indicator that represents an individual's conscious determination to start a new business. Secondary variables included the personality traits measured in the Big Five model (openness to experience, conscientiousness, extraversion, agreeableness, and neuroticism). Survey data were collected from over 500 undergraduate students at a Midwestern university in the United States. The results confirmed that there was a strong positive association between grit and entrepreneurial intentions. Furthermore, independent samples $t$-tests revealed that high grit students showed greater entrepreneurial intent than low grit students. The data also indicated that grit fully mediated the predictive effect of conscientious and neuroticism on entrepreneurial intent. Overall, a better understanding of the influence of grit on entrepreneurial intent, given the presence of various diverse personality constellations, may help inform educators in preparing and delivering course content. The influence of grit may reduce the failure rate of new and young businesses launched by college-educated entrepreneurs.
\end{abstract}

Keywords: Grit, Big Five personality, Entrepreneurship, Entrepreneurial intent, Entrepreneurial education

\section{Background}

This project specifically aims to explore the role that the individual characteristic of grit plays in relation to entrepreneurial intentions. Research in the field of entrepreneurship has placed models of entrepreneurial intentions at the center of our understanding of the entrepreneurial process, and work continues to elaborate on the impact of individual differences on that process. Grit is described as a consistent focus on and enduring attention to the pursuit of long-term goals. As such, grit has been implicated as a predictor of success in a variety of activities and should play a role in entrepreneurial outcomes as well. The purpose of this study was to analyze the relationship between personality traits and entrepreneurial intent considering the influence of grit. Our model makes several contributions to the literature. We introduce grit as a potential mechanism through which personality traits relate to entrepreneurial intent. We compare university students who are high and low in grit on personality variables

(c) The Author(s). 2018 Open Access This article is distributed under the terms of the Creative Commons Attribution 4.0 International License (http://creativecommons.org/licenses/by/4.0/), which permits unrestricted use, distribution, and reproduction in any medium provided you give appropriate credit to the original author(s) and the source, provide a link to the Creative Commons license, and indicate if changes were made. 
and entrepreneurial intent to better understand individual differences. Finally, we provide implications of our findings and suggestions for future research.

\section{Literature review}

\section{Entrepreneurial intent and its antecedents}

Research has demonstrated that intent reliably predicts human action in many circumstances including entrepreneurship (Brice, 2004). According to Zhao, Seibert, and Lumpkin (2010), entrepreneurial intent is "the expressed behavior intention to become an entrepreneur" (p. 383-384). Furthermore, Thompson (2009) described entrepreneurial intent as "... a self-acknowledged conviction by a person that they intend to set up a new business venture and consciously plan to do so at some point in the future" (p. 676). Though an individual's entrepreneurial intent plays an important role in his or her decision to start a new business (Ozaralli \& Rivenburgh, 2016), that intent may or may not lead to entrepreneurial action in starting a business and future success.

Though not all entrepreneurial intent results in entrepreneurial activity, recent popularity in understanding entrepreneurial intent stems from the realization that entrepreneurship is an economic driver. According to the Global Entrepreneurship Monitor (2013), the United States typically demonstrates a high rate of entrepreneurship relative to other developed countries in North America, Europe, and Asia as reported in recent research (Ozaralli \& Rivenburgh, 2016). Lower income countries are looking towards entrepreneurship to spur economic development. Some countries, like Malaysia, are encouraging entrepreneurship with funding and business advisory services (Ismail et al., 2009), and many are looking towards research to help develop entrepreneurs. One branch of entrepreneurial research involves looking into how macro-socioeconomic factors stimulate entrepreneurial intentions; this includes education, media support, and political environments (Alshammari \& Al-Tarawneh, 2016). Another branch of the literature is looking at the success of entrepreneurship education programs and other types of curriculum (Albornoz \& Amorós, 2016; Bae, Qian, Miao, \& Fiet, 2014; Fayolle \& Gailly, 2015). The current study addresses how personality traits and individual differences in grit influence individuals' entrepreneurial intent.

\section{The Big Five}

Goldberg (1993) advocated for a comprehensive framework for the numerous traits that can describe a personality. To this end he used the Big Five personality traits: openness to experience, conscientiousness, extraversion, agreeableness, and neuroticism. Broadly speaking, personality traits precede entrepreneurial intent (Rauch \& Frese, 2007), as they are known to emerge as individual differences as humans develop and then remain quite consistent over time (McCrae and Costa Jr., 2008).

Researchers have attempted to explain entrepreneurial behavior in terms of personality traits, yet there were mixed findings about the presence and strength of the relationships between business creation and success (Rauch \& Frese, 2007). The inconclusiveness of previous research leads researchers to wonder if the Big Five traits are too general, so some researchers have attempted to explain entrepreneurial behavior through more specific traits. This was the conclusion reached in a meta-analysis by Rauch and Frese (2007) who were able to connect entrepreneurial behavior with the constructs of self-efficacy, 
proactivity, innovativeness, and achievement orientation. Based on their findings, they advised future research to further explore those constructs (Rauch \& Frese, 2007).

Rather than focusing on broad traits, some researchers have endeavored to measure personality in narrow traits to attempt to capture the elusive "entrepreneurial personality." For example, Leutner, Ahmetoglu, Akhtar, and Chamorro-Premuzic (2014) found that individuals with an "entrepreneurial personality" tend to be proactive. Regardless, no common set of narrow traits explaining "entrepreneurial personality" have emerged. Rather, recent meta-analytic studies have accumulated the existing evidence of the significant associations that do exist between broad personality traits and entrepreneurship (Zhao \& Seibert, 2006; Zhao et al., 2010; Brandstätter, 2011). To this end, Brandstätter (2011) provided a comprehensive review of each broad trait in terms of entrepreneurial behavior and performance. It should be further noted that there is evidence from meta-analyses that measures of broad personality traits, like the Big Five, do explain variability in entrepreneurial intent (Zhao \& Seibert, 2006). Moreover, those analyses differentiated between entrepreneurs and managers, where entrepreneurs scored higher on conscientiousness and openness to experience than managers (Zhao \& Seibert, 2006). The current study does not attempt to arrive at an "entrepreneurial personality;" rather, it seeks to understand the variability in entrepreneurial intent explainable by broad personality traits, i.e., the Big Five.

\section{Personality and entrepreneurial intentions}

In the past, many studies explored the relationship between entrepreneurs and the Big Five personality traits; however, mixed results suggest more research is needed. For example, a study conducted by Antoncic, Bratkovic Kregar, Singh, and DeNoble (2015) found entrepreneurial intent was associated with individuals who were high in openness, conscientiousness, extraversion, and average on agreeableness. Espíritu-Olmos and Sastre-Castillo (2015) found that personality traits predict entrepreneurial intention, aside from neuroticism, which was negatively related. Brice (2004) reported that people who were exceptionally open to experience or those who were high in conscientious as related positively to entrepreneurial intent. He also found that those high in agreeableness related negatively to entrepreneurial intent. A third study conducted in Malaysia reported openness and extraversion as being significantly positively related to entrepreneurial intent and the rest of the Big Five as not being related at all (Ismail et al., 2009). A positive relationship between openness and entrepreneurial intent and no relationship between neuroticism and entrepreneurial intent is the only consensus in these studies. Table 1 below provides a summary of the findings reported in a number of recent studies involving the link between the Big Five and entrepreneurial intent.

Overall, the main branches of entrepreneurship research are focusing on the influence of broad personality traits. The studies noted above, for instance, indicated that there is a significant relationship between broad personality traits and entrepreneurial intentions. It should be noted however that these findings are not limited to only those personality traits that are commonly associated with entrepreneurial behavior, such as conscientiousness. Indeed, the current study adds to the literature by examining how grit, a construct related to, yet distinct from conscientiousness, influences the entrepreneurial intentions that precede future entrepreneurial actions. To that end, the current study sought to elaborate on the impact of individual differences on the entrepreneurial process, thus bolstering the explanatory power of broad personality traits through grit. 


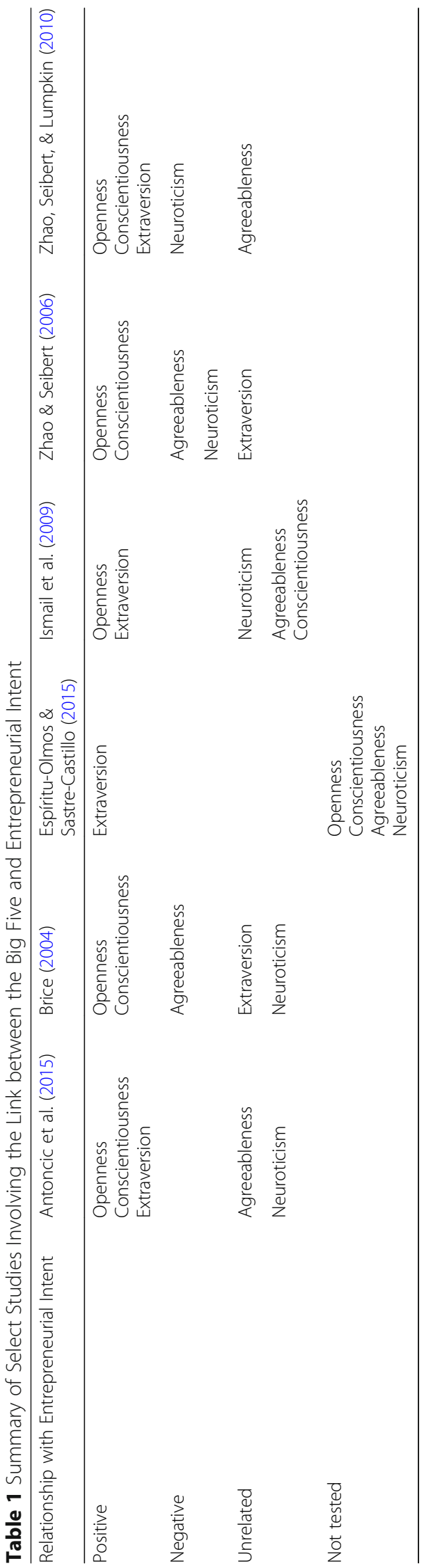


Grit

Grit is defined as, "perseverance and passion for long term goals" (Duckworth et al., 2007). People who have grit stick with their goals for years even when there are setbacks and failures. Duckworth, Peterson, Matthews, and Kelly (2007) conducted research to discover if grit could predict success in various situations. They studied undergraduate student's GPA and SAT scores compared to their grit score. They found that higher grit scores correlated with higher GPAs (Duckworth et al., 2007). Another part of their study centered on finalists in the 2005 Scripps National Spelling Bee. In this study, they compared grit to how far the finalist advanced in the competition, how many hours they studied, previous experience competing in spelling bees, and verbal IQ. The study found that finalists with more grit performed better than non-gritty finalists, due in part to more hours spent studying (Duckworth et al., 2007).

These two studies show that talent or IQ, alone, does not translate to success. It takes grit to be successful. Though two studies are not enough to substantiate this claim; however, researchers have questioned and continue to investigate the predictive value of IQ on success for some time (Alloway \& Alloway, 2010; Hauser \& Huang, 1997). Most people would agree, at least anecdotally, that individuals who work hard with practice and diligence may be successful despite of a lack of natural talent. To this end, grit may provide additional explanatory power for predicting success.

Duckworth and her colleagues (2007) also studied grit in relation to the Big Five personality traits. They found that grit was related to conscientiousness more than any other of the Big Five personality traits. Grit and conscientiousness share variability in their focus on achievement; however, grit is distinct in explaining the unique variability in persevering toward a long-term goal, while conscientiousness is more short-term orientated. Further, grit contributes unique predictive validity over the Big Five.

\section{Grit and entrepreneurial intentions}

Recently, in entrepreneurship research, there has been increasing interest in examining self-regulatory processes in entrepreneurship. Self-regulation is associated with success in a number of different areas of activity. Duckworth and Seligman (2005) reported several ways that self-regulation predicted academic performance and social functioning. Their research suggested that self-regulation was a better indicator of academic performance than intelligence. After reviewing the extant research, Forgas, Baumeister, and Tice (2009) observed that self-regulation is implicated in individual success across a variety of activities.

Forgas and his colleagues (2009) indicated that self-regulation occurred through the individual's control over thoughts, emotions, impulses, motivations, and finally behaviors. As such, an individual effectively selects goals, chooses appropriate strategies and actions to achieve those goals, and attends to feedback in order to monitor progress and adjust actions to stay on course or avoid obstacles.

One specific aspect of self-regulation only recently recognized in the entrepreneurship literature is the individual difference of grit. Grit entails the focus of attention on and stamina in pursuit of long-term goals, which are referred to as consistency of interest and perseverance of effort (Duckworth et al., 2007; Duckworth \& Quinn, 2009; Duckworth \& Eskreis-Winkler, 2013). "Gritty" individuals are those that stick to goals 
with long time horizons, avoid distractions, invest a lot of effort into those goals, and are not deterred by difficulties. Furthermore, research suggests that educators and mentors may be able to influence grit by encouraging individuals not only to work with intensity, but also to build stamina in pursuit of long-term goals (Duckworth et al., 2007), such as the entrepreneurial intent to start a business, which may not materialize for a long time.

Currently, the relationship between grit and entrepreneurial intent has yet to be tested, but the concept is beginning to attract some attention in the field. For instance, Morris, Webb, Fu, and Singhal (2013) used measures of grit within a larger construct labeled tenacity to evaluate the effectiveness of an entrepreneurial educational program. Measures of several individual characteristics in addition to tenacity were used on a group of students before and after a consulting engagement with entrepreneurs. The researchers found that the educational experience resulted in improvement in those measures. In another article, Nambisan and Baron (2013) argued that self-regulatory processes should be especially related to entrepreneurship within innovation ecosystems. Innovation ecosystems are competitive environments in which the member organizations share a common set of technologies, knowledge, or skills. Such environments require entrepreneurs to balance the long-term interests of their own ventures against the shared interests of the ecosystem. Nambisan and Baron identified grit as one of the self-regulatory processes they considered to be important. Even with this endorsement, grit has yet to be studied in relation individual entrepreneurship outcomes.

\section{The current study}

A well-established entrepreneurial indicator is entrepreneurial intention, which is an individual's conscious determination and planning to form a new venture. Built on the work of Ajzen and Fishbein (1975), models of entrepreneurial intentions propose that intentions significantly predict entrepreneurial behavior by focusing an individual's attention and thought on the decisions involved in that behavior. Moreover, a variety of factors can undergird intentions for behavior including attitudes and norms, perceptions about and confidence of the individual's control over that behavior, the attractiveness of the behavior, and the individual's action orientation (Bird, 1988; Bird \& Jelinek, 1988; Krueger, 1993; Krueger \& Brazeal, 1994; Shapero \& Sokol, 1982). Simply stated, entrepreneurial intentions precede entrepreneurial actions.

Overall, this study aims to explore the influence of grit on entrepreneurial intentions (i.e., an individual's inclination to start new businesses). In particular, a better understanding of grit, personality traits, and entrepreneurial intentions may inform business educators.

\section{Hypotheses development}

Our literature review, highlighting previous work by Duckworth et al. (2007), suggested a link between grit and the Big Five, particularly conscientiousness. Additionally, a number of studies have examined associations between the Big Five and entrepreneurial behavior (e.g., Civarella et al., 2003; Leutner et al., 2014; Zhao \& Seibert, 2006). A final consideration is the background characteristics of the sample. Duckworth et al. (2007) found a positive association between grit and age. In this study, background 
information was collected on participants' age and the number of business classes they have taken. The following hypothesis further explores these relationships:

H1: Significant intercorrelations exist among the study variables (participants' age, the number of business classes they had taken, the Big Five, grit, and entrepreneurial intent).

As stated above, there is an overt link between grit and conscientiousness; however, there is less evidence to explain the relationship between the remaining personality traits and grit and the direction of the relationships. This study tested the following hypothesis to determine if group segmentation according to grit provided a meaningful differentiator for comparing means scores on the Big Five, which are established as relatively stable personality traits.

H2: Mean scores on the Big Five personality traits (openness, extraversion, agreeableness, and neuroticism) will be significantly different between students with high grit scores and those with low grit scores.

Grit, like personality is an individual difference variable; however, unlike personality Duckworth et al. (2007) purported that grit may be influenced (e.g., through educational interventions) and changed over time. In this cross-sectional study, we sought to understand how grit exerts influence through various personality styles. Though our data in the current study is from one snapshot in time, our model suggests that grit is a potential mechanism of change, hence we propose it is a prospective mediator. Further, grit is persistence towards a long-term goal, such as intent to start a new venture (i.e., entrepreneurial intent), which leads to the following additional hypothesis:

H3: A group of students who are higher in grit are expected to have higher mean scores on entrepreneurial intent than a group lower in grit.

Duckworth et al. (2007) also identified mediational relationships involving deliberate practice, grit, and performance. They concluded that grittier students were less put off by hard practice, which is the most significant predictor of long-term performance gains. As such, the final hypothesis postulated that:

H4: The relationship between the Big Five personality traits and entrepreneurial intent will be mediated by grit.

\section{Methods}

Ethical approval for this project was provided by the Institutional Review Board (IRB) at the university where the research was conducted. All participating students indicated their consent directly on the online survey prior to completing the question battery. No vulnerable populations were involved in this study.

\section{Participants and procedure}

The participants for this study were purposefully selected from a target population of individuals who may exhibit entrepreneurial intentions. These individuals were university 
students recruited from a 300-level business course, Principles of Management, offered at a large Midwestern university in the United States. Participants' level of familiarity with business topics and concepts may vary based on the number and types of courses they have taken. Either previously or concurrently, students completed common core business content, including accounting, business law, economics, finance, and management.

The data collection procedures were limited to asynchronous participation in an online survey. Given that the survey was administered online, participants were free to complete the survey at a time and place that was convenient for them. The survey contained 200 questions and took participants approximately 30 minutes to complete. In order to obtain a sample with adequate statistical power, data collection was conducted for two consecutive semesters (Fall 2015 and Spring 2016).

In total, 555 students accessed the online survey. Although not all participants provided a complete response, all cases were retained for analysis whenever possible. Incomplete responses were addressed using pairwise deletion. The sample consisted of 360 males and 160 females ( 2 other, 33 missing). Participants' mean age was 22 ( $S D=$ 4.78). In terms of class rank, 3 participants identified as freshmen, 95 as sophomores, 195 as juniors, and 214 as seniors (17 other, 31 missing). The sample was $81 \%$ White, 7\% Asian, 3\% Black, 2\% Hispanic, and 2\% Indigenous Peoples (5\% other).

Measures

\section{Entrepreneurial intent}

Thompson's (2009) 10-item Individual Entrepreneurial Intent scale was used to measure participants' self-acknowledged conviction that they intended to start a business at some point in the future. An example item was, "Thinking of yourself, how true or untrue is it that you intend to set up a company in the future" ( $1=$ Very untrue, $6=$ Very true). The scale was found to have sufficient internal reliability with a Cronbach's alpha of 0.77 .

Grit

Participants' grit was measured using 12-item scale created by Duckworth et al. (2007). Items on this scale were evenly distributed between two subscales: Grit Interest and Grit Effort. Prior to analysis, these subscales were summed into a composite index in which higher scores indicated greater grit (Duckworth et al., 2007). An example item was, "I have overcome setbacks to conquer an important challenge" ( $1=$ Not at all like me, 5 = Just like me). The Cronbach's alpha for the grit scale was 0.82 .

\section{Big Five personality traits}

The Big Five personality traits were measured using a 10-item measure of the Big Five personality domains (BFI-10; Rammstedt \& John, 2007). To this end, participants were asked to evaluate a key phrase that followed the prompt "I see myself as someone who ..." ( 1 = Disagree Strongly, 5 = Agree Strongly). Example items were the key phrase that completed each question. The key phrases varied for each subscale. It was "... has an active imagination" for openness; "... gets nervous easily" for neuroticism; “... does a thorough job" for Conscientiousness; “... tends to find fault” for agreeableness (reverse coded); and “... is reserved" for extraversion (reverse coded). Each subscale exceeded Nunnally's (1978) reliability guideline of .7 or above. 


\section{Results}

A preliminary factor analysis was conducted using SPSS 24 to determine if there was sufficient dimensionality to differentiate grit and conscientiousness. The results indicated a multi-factor solution in which the items separated out into separate factors (see Table 2). This suggested that grit and conscientiousness had good psychometric quality and that it was appropriate to treat them as distinct latent constructs for the analyses described below.

First, Pearson correlations were calculated to test the bivariate relationships between participants' age, the number of business classes they had taken, the Big Five, grit, and entrepreneurial intent.

The data was then split into quartiles based on participants' grit scores. Students with scores in $\mathrm{Q}_{1}$ were defined as the Low Grit group, and those with scores in $\mathrm{Q}_{4}$ were defined as the High Grit group. Thereafter, a second battery of independent samples $t$-tests were used to compare the high and low grit students in terms of the Big Five and entrepreneurial intentions.

Mediational analyses were used to determine the degree to which grit mediated the effects of the Big Five on entrepreneurial intent. Theses analyses were conducted using the complete dataset.

\section{Correlations}

Pearson correlations were performed using all available cases (see Table 3). For the most part, the predicted associations were confirmed. In terms of the background variables, the

Table 2 Eigenvalues, Percentages of Variance, and Factor Loadings for Grit Interest, Grit Effort, and Conscientiousness

\begin{tabular}{|c|c|c|c|c|}
\hline \multirow[t]{2}{*}{ Items } & \multicolumn{3}{|c|}{ Factor Loading } & \multirow[t]{2}{*}{ Communality } \\
\hline & $\begin{array}{l}\text { Factor } \\
1\end{array}$ & $\begin{array}{l}\text { Factor } \\
2\end{array}$ & $\begin{array}{l}\text { Factor } \\
3\end{array}$ & \\
\hline \multicolumn{5}{|l|}{ Grit Interest } \\
\hline 1. I often set a goal but later choose to pursue a different one. (R) & .67 & & & .49 \\
\hline $\begin{array}{l}\text { 2. I have been obsessed with a certain idea or project for a short } \\
\text { time but later lost interest. (R) }\end{array}$ & .77 & & & .65 \\
\hline 5. My interests change from year to year. (R) & .75 & & & .59 \\
\hline 6. I become interested in new pursuits every few months. (R) & .80 & & & .67 \\
\hline \multicolumn{5}{|l|}{ Grit Effort } \\
\hline 1. I finish whatever I begin. & & .66 & & .55 \\
\hline 2. Setbacks don't discourage me. & & .83 & & .69 \\
\hline 3. I am diligent. & & 65 & & .62 \\
\hline 4. I am a hard worker. & & .61 & & .56 \\
\hline \multicolumn{5}{|l|}{ Conscientiousness } \\
\hline 1. I see myself as someone who tends to be lazy. (R) & & & .74 & .60 \\
\hline 2. I see myself as someone who does a thorough job. & & & .71 & .57 \\
\hline Eigenvalue & 2.31 & 2.10 & 1.57 & \\
\hline$\%$ of variance & $23.13 \%$ & $20.99 \%$ & $15.67 \%$ & \\
\hline
\end{tabular}

Note. $R=$ reverse-coded items. Items 3 and 4 of the Grit Interest subscale and Items 5 and 6 of the Grit Effort subscale were found to be highly repetitive with other items. Therefore, they were removed to improve the factor loadings of the remaining items. All of the other analyses were performed using the complete grit scale, which included the items that were removed for factor analysis 
Table 3 Significant Intercorrelations Among Study Variables

\begin{tabular}{|c|c|c|c|c|c|c|c|c|c|}
\hline & 1 & 2 & 3 & 4 & 5 & 6 & 7 & 8 & 9 \\
\hline 1. Age & - & & & & & & & & \\
\hline 2. Number of Business Classes Completed & .19 & - & & & & & & & \\
\hline 3. Extraversion & & & - & & & & & & \\
\hline 4. Agreeableness & & .15 & & - & & & & & \\
\hline 5. Conscientious & & .10 & & .16 & - & & & & \\
\hline 6. Neuroticism & & & -.15 & -.18 & -.25 & - & & & \\
\hline 7. Openness & & & -.57 & & & & - & & \\
\hline 8. Grit & & .14 & & .24 & .49 & -.33 & & - & \\
\hline 9. Entrepreneurial Intent & .17 & & & & .12 & -.09 & .22 & .16 & - \\
\hline
\end{tabular}

Note. All correlations significant at the 0.01 level

data indicated a positive correlation between participants' age and the number of business classes they have taken. Further, older students exhibited greater entrepreneurial intent. Surprisingly, there was no significant correlation between age and grit. Grit was, however, positively correlated to the number of business classes that students had taken. This suggested that students who take lots of business courses are likely to have a high grit score as well. Students with a high mean score for grit were also found to have a high mean score for entrepreneurial intent. Lastly, correlations between the Big Five and grit were positive for agreeableness and conscientiousness and negative for neuroticism.

\section{Independent samples $t$-tests}

A set of independent samples $t$-tests were performed to determine if students' Big Five and entrepreneurial intent scores differed significantly between students with high grit and those with low grit (see Table 4). In comparison with the low grit students, the high grit group was found to have higher means scores for agreeableness and conscientiousness, and lower means scores for neuroticism. Furthermore, it was found that the high grit students had higher means scores for entrepreneurial intent than their counterparts in the low grit group. This difference is exceptionally noteworthy given that the overarching purpose of this study was to better understand the relationship between grit and entrepreneurial intentions.

Table 4 Comparison of Students with High Grit Scores and those with Low Grit Scores

\begin{tabular}{|c|c|c|c|c|c|c|}
\hline \multirow{3}{*}{ Dependent Variable } & \multicolumn{4}{|c|}{ Independent Variables: Grit } & \multirow[b]{3}{*}{$t$} & \multirow[b]{3}{*}{$p$} \\
\hline & \multicolumn{2}{|c|}{$\begin{array}{l}\text { Low Grit } \\
\left(\text { Scores below } Q_{1}\right)\end{array}$} & \multicolumn{2}{|c|}{$\begin{array}{l}\text { High Grit } \\
\left(\text { Scores above } Q_{3}\right)\end{array}$} & & \\
\hline & $M$ & $S D$ & $M$ & $S D$ & & \\
\hline Extraversion & 2.89 & 0.79 & 3.02 & 0.76 & 1.48 & .141 \\
\hline Agreeableness & 3.37 & 0.67 & 3.81 & 0.62 & 5.52 & $.000^{* * *}$ \\
\hline Conscientious & 3.26 & 0.71 & 4.13 & 0.60 & 10.86 & $.000^{* * *}$ \\
\hline Neuroticism & 3.07 & 0.76 & 2.43 & 0.73 & -6.96 & $.000^{* * *}$ \\
\hline Openness & 3.36 & 0.82 & 3.42 & 0.87 & 0.56 & .573 \\
\hline Entrepreneurial Intent & 3.30 & 0.95 & 3.63 & 0.98 & 2.80 & $.005^{* *}$ \\
\hline
\end{tabular}

Note. ${ }^{* *} p<.001 ;{ }^{* *} p<.01$ (two-tailed); Low Grit $n=149$, High Grit $n=128$; $d f$ may vary because incomplete responses were addressed using pairwise deletion 


\section{Mediational analysis}

The mediation analyses followed a three-step multiple regression model (Baron \& Kenny, 1986). In step one, bivariate regressions were performed to test the predictive effect of the Big Five personality traits on entrepreneurial intent (IV $\rightarrow$ Entrepreneurial Intent). In step two, bivariate regressions were used to test the predictive effect of the Big Five personality traits on grit (IV $\rightarrow$ Grit). Finally, simultaneous multiple regressions were used to test the predictive effects of grit along with the Big Five personality trait in question on entrepreneurial intent (IV, Grit $\rightarrow$ Entrepreneurial Intent). The significance of the observed effects was tested using 95\% bootstrap confidence intervals (Preacher \& Hayes, 2004).

The results of these analyses were used to identify various predictive and mediational relationships. A direct effect without mediation indicated that the Big Five personality trait in question significantly predicted entrepreneurial intent with no mediation by grit. Indirect effects implied that the effect of the Big Five personality trait on entrepreneurial intent was in some way mediated by grit. The observed predictive relationship after the mediator (i.e. grit) was added indicated either (a) full mediation, wherein the direct effect became nonsignificant; (b) partial mediation, wherein the direct effect reduced in magnitude; or (c) no mediation, wherein the direct effect remained significant and did not reduce in magnitude.

In this study, mediational analyses were used to determine the degree to which grit mediated the effects of the Big Five on entrepreneurial intent (see Table 5). Ultimately, openness, conscientiousness, and neuroticism predicted grit. In particular, the results indicated that grit fully mediated the positive effect of conscientious on entrepreneurial intent. Likewise, grit fully mediated the negative effect of neuroticism on entrepreneurial intent. This suggested that grit is a factor influencing students' entrepreneurial intentions (see Fig. 1). Openness had a direct positive effect on entrepreneurial intentions, but there was no predictive relationship between openness and grit. In terms of extraversion, the direct effects were nonsignificant for both entrepreneurial intent or grit. Lastly, the results indicated that while agreeableness failed to predict entrepreneurial intentions, it was significantly related to grit. To our knowledge, no previous studies had sought to examine whether or not grit mediated the effects of the Big Five on entrepreneurial intent.

Independent samples $t$-tests showed that students with high grit scores exhibited greater entrepreneurial intent than those with low grit scores. The most notable finding of the mediation analysis was that grit fully mediated the predictive effect of conscientious and neuroticism on entrepreneurial intent.

Table 5 Tests of Mediational Relationships for All Cases

\begin{tabular}{|c|c|c|c|c|c|c|}
\hline \multirow[t]{2}{*}{ Variable } & \multirow{2}{*}{$\begin{array}{l}\text { IV } \rightarrow \\
\text { Entrepreneurial } \\
\text { Intent }\end{array}$} & \multirow[t]{2}{*}{$\begin{array}{l}\mathrm{IV} \rightarrow \\
\text { Grit }\end{array}$} & \multicolumn{3}{|c|}{$\begin{array}{l}\text { IV, Grit } \\
\rightarrow \text { Entrepreneurial Intent }\end{array}$} & \multirow[t]{2}{*}{$\begin{array}{l}\text { Final } \\
\text { model } R^{2}\end{array}$} \\
\hline & & & Grit alone & IV & Grit & \\
\hline Conscientiousness & $.12^{* *}$ & $.49^{* * *}$ & $.16^{* * *}$ & .04 & $.14^{* *}$ & $.03^{* * *}$ \\
\hline Neuroticism & $-.09^{*}$ & $-.33^{* * *}$ & $.16^{* * *}$ & -.04 & $.15^{* *}$ & $.03^{* * *}$ \\
\hline Openness & $.22^{* * *}$ & .04 & $.16^{* * *}$ & $.20^{* * *}$ & $.15^{* * *}$ & $.07^{* * *}$ \\
\hline Agreeableness & .04 & $.24^{* * *}$ & $.16^{* * *}$ & -.01 & $.18^{* * *}$ & $.03^{* * *}$ \\
\hline Extraversion & -.06 & .06 & $.16^{* * *}$ & -.05 & $.17^{* * *}$ & $.03^{* * *}$ \\
\hline
\end{tabular}

Note. ${ }^{*} p<.05,{ }^{* *} p<.01,{ }^{* * *} p<.001$ (two-tailed) 
Direct effect

Mediational results

-ーーーーーーーーー

Standardized regression coefficients $(\beta)$

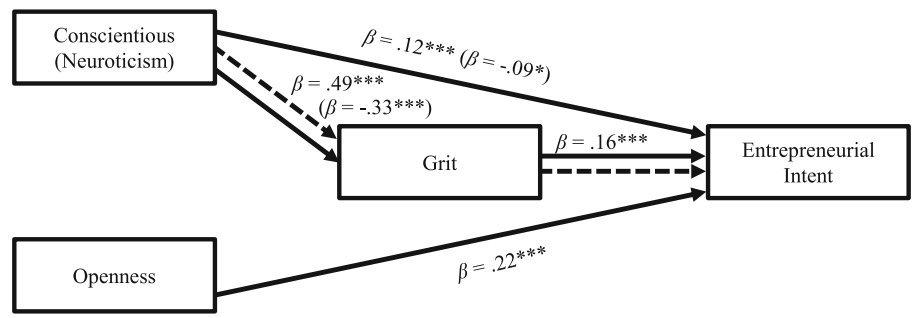

Fig. 1 Mediational relationships among the Big Five personality traits, grit, and entrepreneurial intent. ${ }^{*} p<.05$, ${ }^{* *} p<.01,{ }^{* * *} p<.001$ (two-tailed)

\section{Discussion}

This study found that individuals higher in grit are higher in conscientiousness and agreeableness and lower in neuroticism. This provides a noteworthy connection to Zhao and Seibert's (2006) study, which found that entrepreneurs relate positively to conscientiousness and negatively to neuroticism. Moreover, the second battery of independent samples $t$-tests reported in the present study revealed that students with high grit scores exhibited greater entrepreneurial intent than those with low grit scores. This aligns the work of Nambisan and Baron (2013) who identified grit as one of several self-regulatory processes needed to support entrepreneurship within innovation ecosystems. As such, this study makes an important contribution in that it substantiates the notion that grit is a meaningful variable for comparing entrepreneurial intentions between groups.

The results of this study are intriguing in that extraversion and entrepreneurial intent were not significantly correlated. This finding is inconsistent with some previous research involving entrepreneurial intent and the Big Five. In particular, Zhao, Seibert, and Lumpkin (2010) and Espíritu-Olmos and Sastre-Castillo (2015) found a positive relationship between extraversion and entrepreneurial intent. Results did, however, coincide with Zhao et al. (2010) in that conscientiousness, openness, emotional stability (reverse coded neuroticism) had a positive relationship with entrepreneurial intent.

Since the sample consisted of college students focusing on entrepreneurial intent, it may be that, in this population, students with more extraverted personalities are focused on positive emotion, sociability, energy, and stimulation in their current environment. Entrepreneurial intent has a future focus; this may explain the lack of correlation between extraversion and entrepreneurial intent in the current sample. However, that same future focus does make sense considering that grit (i.e., the perseverance toward a long-term goal) may be more appealing to conscientious personalities who are less focused on stimulus seeking in their current environment.

The mediating relationship of grit suggests that business education, that teaches grit, may influence entrepreneurial intent. Oosterbeek, Van Praag, and Ijsselstein (2010) observed that business education allows students to be more realistic about what is needed to start a business, essentially suggesting that endurance (i.e., grit) development should be a cornerstone of the curriculum. On the other hand, Bae et al. (2014) found that an 
individual's intent to become an entrepreneur was not significantly changed after taking an entrepreneurship class. The findings from our study identifying personality as an antecedent may offer important information to educators, coaches, and mentors seeking to tailor interventions to foster grit. Continuing to build on our initial model (i.e., personality traits, grit, and the entrepreneurial intent of emerging entrepreneurs) will also provide fruitful avenues for future research. Further, the model could be tested with other populations, including more diverse ones, to test the generalizability of what was found in this study.

Our results foreshadow the expectation that individuals with both entrepreneurial intent and grit may be better suited for entrepreneurial activity, though these relationships require testing in future research. Our results both make an important contribution to the current literature on the antecedents of entrepreneurial intent and suggest future work to make connections to subsequent entrepreneurial activity.

\section{Implications}

Grit is beneficial in many situations. In a study of university students, Lucas, Gratch, Cheng, and Marsella (2015) found that grittier participants increased their effort in a losing situation compared to less gritty participants. In particular, Lucas et al. (2015) found that grittier people are more optimistic when failing and that is why they continue to put forth more effort. These results agree with Duckworth et al. (2007) who stated that grit differentiates people in failing situations. Given the fierce competitive environment facing new and young businesses, it isn't unrealistic to assume that grittier entrepreneurs will be more successful. This line of reasoning gives way to one important question: Can grit be taught? To date, there has been no research in this area; however, this study aims to improve business education by encouraging faculty to infuse grit into their entrepreneurial content. This can be done in a number of ways.

First, practitioners should teach students strategies for setting goals (Willingham, 2016). Grit requires perseverance toward a long-term goal. As such, learning to set good goals is the first step in developing grit in students. Second, instructors should share real life examples with the students of people who had to be gritty to succeed (Smith, 2014). Two examples of people in this group are Steve Jobs and Walt Disney. They both had to endure many setbacks and rejections before they became successful. According to Pappano (2013), exposing students to real-life cases where grit is easily observed gives students the message that they can be successful in spite of hardship. Lastly, it is important to teach students that ability and competence grow with effort (Tough, 2016). This is primarily done by providing detailed feedback on students' academic behaviors. Ultimately, the goal is to show students that performance can improve with practice. This belief is essential as it provides students with the motivation necessary to endure otherwise imperceptible progress.

\section{Limitations}

While the study contributes to the entrepreneurship literature, we include noteworthy limitations of the study. For example, due to the cross-sectional nature of the study, inferences of causality need to be verified with longitudinal research. Accounting for the business and entrepreneurial experiences of the students in the sample would strengthen the study; however, data was not collected on exactly what courses were completed by each individual at the time of the study. Another limitation to the 
generalizability of the findings is that the dependent variable in the study is entrepreneurial intent, which does not necessarily translate into entrepreneurial action, business start-up, and eventual business success. However, our study does suggest potential future research questions worth exploring and these questions would best be researched longitudinally.

\section{Conclusion}

Overall, this study examined the relationship between personality traits and entrepreneurial intent considering the influence of grit. Our study made a unique contribution in that we introduced grit as a potential mechanism through which personality traits relate to entrepreneurial intent. The results confirmed that there was a strong positive association between grit and entrepreneurial intentions. It was also found that grit shared a significant positive correlation with both agreeableness and conscientiousness. Conversely, there was a significant negative correlation between grit and neuroticism. When the sample was segmented into high and low grit participants, the high grit participants emerged as having significantly higher means scores for entrepreneurial intent than their counterparts in the low grit group. We also found that in comparison with the low grit group, high grit participants had higher means scores for agreeableness and conscientiousness, and lower means scores for neuroticism. Lastly, the data indicated that grit fully mediated the predictive effect of conscientious and neuroticism on entrepreneurial intent.

These findings will become increasingly important as research in the field of entrepreneurship continues to place models of entrepreneurial intentions at the center of our understanding of the entrepreneurial process. As we learn more about entrepreneurial intent and its antecedents, it is likely that post-secondary institutions will want to make every effort to reduce the failure rate of new and young businesses launched by college-educated entrepreneurs. Ideally, grit will become an inherent component of the learning environment experienced by university students. This in turn will result in more entrepreneurs and more successful entrepreneurs, leading to new business creation that will help to grow local economies.

Acknowledgements

Not applicable to this manuscript. There were no individuals who contributed to this manuscript who did not meet the criteria for authorship.

\section{Availability of data and materials}

The dataset upon which the conclusion of this manuscript rely will be made publicly available via additional supporting files that can be provided upon request.

Authors' contributions

NTB contributed to data collection, performed data analysis, and assisted in writing the manuscript. SH performed data analysis and assisted in writing the manuscript. PLS contributed to data collection and assisted in writing of the manuscript. MMW performed data analysis and assisted in writing of the manuscript. All authors read and approved the final manuscript.

\section{Competing interests}

The authors of this paper have no financial and non-financial competing interests that could influence the interpretation of data or presentation of information.

\section{Publisher's Note}

Springer Nature remains neutral with regard to jurisdictional claims in published maps and institutional affiliations. 
Received: 17 January 2018 Accepted: 16 May 2018

Published online: 04 June 2018

References

Ajzen, I, \& Fishbein, M (1975). Belief, attitude, intention and behavior: An introduction to theory and research. Reading, MA: Addison-Wesley.

Albornoz, C, \& Amorós, JE. (2016). 3. Does entrepreneurship education change minds? A multinational analysis of mandatory and voluntary entrepreneurial training. Annals of Entrepreneurship Education and Pedagogy, 60-82.

Alloway, TP, \& Alloway, RG. (2010). Investigating the predictive roles of working memory and IQ in academic attainment. Journal of Experimental Child Psychology, 106(1), 20-29. https://doi.org/10.1016/j.jecp.2009.11.003.

Alshammari, M, \& Al-Tarawneh, Kl. (2016). Women and entrepreneurship in the third world. European J Business Manag, $8(7), 11-15$

Antoncic, B, Bratkovic Kregar, T, Singh, G, DeNoble, AF. (2015). The big five personality-entrepreneurship relationship: Evidence from Slovenia. Journal of Small Business Management, 53(3), 819-841.

Bae, TJ, Qian, S, Miao, C, Fiet, JO. (2014). The relationship between entrepreneurship education and entrepreneurial intentions: A meta-analytic review. Entrepreneurship Theory and Practice, 38(2), 217-254.

Baron, RM, \& Kenny, DA. (1986). The moderator-mediator variable distinction in social psychological research: Conceptual, strategic, and statistical considerations. Journal of Personality and Social Psychology, 51(6), 1173-1182. https://doi.org/10.1037/0022-3514.51.6.1173.

Bird, B. (1988). Implementing entrepreneurial ideas: The case for intention. Academy of Management Review, 13, 442-453.

Bird, B, \& Jelinek, M. (1988). The operation of entrepreneurial intentions. Entrepreneurship Theory and Practice, 13(2), 21-29.

Brandstätter, H. (2011). Personality aspects of entrepreneurship: A look at five meta-analyses. Personality and Individual Differences, 51, 222-230.

Brice, J. (2004). The role of personality dimensions on the formation of entrepreneurial intentions. In Annual USASBE National Conference, (Vol. 18)

Duckworth, AL, \& Eskreis-Winkler, L. (2013). True grit. The Observer, 26, 1-3.

Duckworth, AL, Peterson, C, Matthews, MD, Kelly, DR. (2007). Grit: Perseverance and passion for long-term goals. Journal of Personality and Social Psychology, 92(6), 1087-1101.

Duckworth, AL, \& Quinn, PD. (2009). Development and validation of the short grit scale (grit-S). Journal of Personality Assessment, 91(2), 166-174. https://doi.org/10.1080/002238908026342.

Duckworth, AL, \& Seligman, MEP. (2005). Self-discipline outdoes IQ in predicting academic performance of adolescents. Psychological Science, 16(12), 939-944.

Espíritu-Olmos, R, \& Sastre-Castillo, MA. (2015). Personality traits versus work values: Comparing psychological theories on entrepreneurial intention. Journal of Business Research, 68(7), 1595-1598.

Fayolle, A, \& Gailly, B. (2015). The impact of entrepreneurship education on entrepreneurial attitudes and intention: Hysteresis and persistence. Journal of Small Business Management, 53(1), 75-93.

Forgas, JP, Baumeister, RF, Tice, DN (2009). The psychology of self-regulation. Sydney: Psychology Press Limited.

Global Entrepreneurship Monitor. (2013). Key indicators. Retrieved from http://www.gemconsortium.org/data

Goldberg, LR. (1993). The structure of phenotypic personality traits. American Psychologist, 48(1), 26-34.

Hauser, RM, \& Huang, M-H. (1997). Verbal ability and socioeconomic success: A trend analysis. Social Science Research, 26(3), 331-376. https://doi.org/10.1006/ssre.1997.0604.

Ismail, M, Khalid, SA, Othman, M, Jusoff, HK, Rahman, NA, Kassim, KM, Zain, RS. (2009). Entrepreneurial intention among Malaysian undergraduates. Int J Business Manag, 4(10), 54.

Krueger, N. (1993). The impact of prior entrepreneurial exposure on perceptions of new venture feasibility and desirability. Entrepreneurship Theory and Practice, 18(1), 5-21.

Krueger, N, \& Brazeal, DV. (1994). Entrepreneurial potential and potential entrepreneurs. Entrepreneurship Theory and Practice, 18(3), 91-104.

Leutner, F, Ahmetoglu, G, Akhtar, R, Chamorro-Premuzic, T. (2014). The relationship between the entrepreneurial personality and the big five personality traits. Personality and Individual Differences, 63, 58-63.

Lucas, GM, Gratch, J, Cheng, L, Marsella, S. (2015). When the going gets tough: Grit predicts costly perseverance. Journal of Research in Personality, 59, 15-22.

McCrae, RR, \& Costa Jr, PT (2008). The five-factor theory of personality. In OP John, RW Robins, LA Pervin (Eds.), Handbook of personality: Theory and research. New York: Guilford Press.

Morris, MH, Webb, JW, Fu, J, Singhal, S. (2013). A competency-based perspective on entrepreneurship education: Conceptual and empirical insights. Journal of Small Business Management, 51(3), 352-369.

Nambisan, S, \& Baron, RA. (2013). Entrepreneurship in innovation ecosystems: Entrepreneurs' self-regulatory processes and their implications for new venture success. Entrepreneurship: Theory \& Practice, 37(5), 1071-1097.

Nunnally, JC (1978). Psychometric theory, (2nd ed.). San Francisco: Jossey-Bass.

Oosterbeek, H, Van Praag, M, ljsselstein, A. (2010). The impact of entrepreneurship education on entrepreneurship skills and motivation. European Economic Review, 54(3), 442-454.

Ozaralli, N, \& Rivenburgh, NK. (2016). Entrepreneurial intention: antecedents to entrepreneurial behavior in the U.S.A. and Turkey. Journal of Global Entrepreneurship Research, 6(1), 3. https://doi.org/10.1186/s40497-016-0047-x.

Pappano, L. (2013). 'Grit' and the new character education. Harvard Education Digest, 29(1), 4-9.

Preacher, K, \& Hayes, A. (2004). SPSS and SAS procedures for estimating indirect effects in simple mediation models. Behavior Research Methods, Instruments, \& Computers, 36(4), 717-731. https://doi.org/10.3758/BF03206553.

Rammstedt, B, \& John, OP. (2007). Measuring personality in one minute or less: A 10 item short version of the big five inventory in English and German. Journal of Research in Personality, 41(1), 203-212.

Rauch, A, \& Frese, M. (2007). Let's put the person back into entrepreneurship research: A meta-analysis on the relationship between business owners' personality traits, business creation, and success. European Journal of Work and Organizational Psychology, 16(4), 353-385. 
Shapero, A, \& Sokol, L (1982). The social dimensions of entrepreneurship. In CA Kent et al. (Eds.), The encyclopedia of entrepreneurship, (pp. 72-90). Englewood Cliffs, NJ: Prentice-Hall.

Smith, T (2014). Does teaching kids to get 'gritty' help them get ahead. [Radio broadcast]. All Things Considered. Washington, DC.

Thompson, ER. (2009). Individual entrepreneurial intent: Construct clarification and development of an internationally reliable metric. Entrepreneurship Theory and Practice, 33(3), 669-694.

Tough, P. (2016). How kids learn resilience. The Atlantic, 317(5), 56-66.

Willingham, DT. (2016). Ask the cognitive scientist: 'Grit' is trendy, but can it be taught? American Educator, 29(2), 31-35.

Zhao, H, \& Seibert, SE. (2006). The big five personality dimensions and entrepreneurial status: A meta-analytical review. Journal of Applied Psychology, 91(2), 259-271.

Zhao, H, Seibert, SE, Lumpkin, GT. (2010). The relationship of personality to entrepreneurial intentions and performance: A meta-analytic review. Journal of Management, 36(2), 381-404.

Submit your manuscript to a SpringerOpen ${ }^{\circ}$ journal and benefit from:

- Convenient online submission

- Rigorous peer review

- Open access: articles freely available online

- High visibility within the field

- Retaining the copyright to your article

Submit your next manuscript at $\gg$ springeropen.com 